MAÍRA MELLO REZENDE VALLE

\title{
A EXPRESSÃO E ATIVIDADE DA NAD(P)H OXIDASE EM ILHOTAS PANCREÁTICAS DE RATOS TRATADOS COM DIETA HIPERLIPÍDICA
}

\footnotetext{
Dissertação apresentada ao Programa de Pós-graduação em Fisiologia Humana do Instituto de Ciências Biomédicas da Universidade de São Paulo, para obtenção do Título de Mestre em Ciências.
}

\section{São Paulo}

2009 


\title{
RESUMO
}

\author{
VALLE, MMR. A expressão e a atividade da NAD(P)H oxidase em ilhotas \\ pancreáticas de ratos tratados com dieta hiperlipídica. 2009. 72 f. Dissertação - \\ Instituto de Ciências Biomédicas, Universidade de São Paulo, São Paulo, 2009.
}

Nos últimos anos, com a mudança do estilo de vida da população, que inclui uma dieta rica em gordura e inatividade física, aumentou o número de pessoas com síndrome metabólica. Esta se caracteriza por obesidade abdominal, resistência à insulina, hipertensão, níveis de triglicérides altos e o colesterol HDL baixo. Há muitos modelos para estudo de síndrome metabólica e de suas disfunções. Um deles constitui-se no uso de dieta hiperlipídica, simulando uma condição ambiental humana. O tipo de gordura utilizado influencia na resposta obtida. Para gerar obesidade e resistência à insulina é muito utilizada a banha de porco, pois esta possui uma ação bastante deletéria sobre os animais. Este tipo de dieta também gera disfunção das células $\beta$ do pâncreas, caracterizada pela diminuição da secreção de insulina in vitro e in vivo e até mesmo diminuição da expressão de seu RNAm e proteína, o qual é um fator de risco para o diabetes mellitus. Outro fator que pode contribuir para a disfunção do pâncreas é o estresse oxidativo, ao qual estas células são muito sensíveis por possuírem poucas defesas antioxidantes. Em tecidos como o cerebral, o hepático, o adiposo, o renal e a aorta de animais tratados com dieta hiperlipídica já se observou aumento de expressão e/ou atividade da NAD(P)H oxidase. Conseqüentemente, esta enzima pode estar envolvida em processos fisiopatológicos de doenças como a hipertensão arterial, a doença hepática gordurosa não alcoólica, as demências e a resistência periférica à insulina. Além disso, em ilhotas de ratos OLEFT e camundongos db/db, ambos diabéticos tipo 2, foi verificado estresse oxidativo e aumento da expressão da enzima, sugerindo que ela tenha um papel na disfunção das células $\beta$. Também há evidências de sua participação em processos fisiológicos como a secreção de insulina. Deste modo, o objetivo do presente trabalho foi avaliar se a dieta hiperlipídica altera a expressão e/ou a atividade da $\mathrm{NAD}(\mathrm{P}) \mathrm{H}$ oxidase em ilhotas pancreáticas e se este fato pode estar associado às disfunções das células $\beta$ já relatadas na literatura para este modelo animal. Nossos resultados demonstram que a dieta foi efetiva em promover um quadro semelhante à síndrome metabólica, já que os animais apresentaram obesidade abdominal, pressão arterial sistólica elevada, HDL-colesterol diminuído, 
glicemia sanguínea em jejum aumentada, hiperinsulinemia e intolerância à glicose. Entretanto, as ilhotas pancreáticas dos animais que receberam dieta hiperlipídica não apresentaram estresse oxidativo, apresentaram menos apoptose, maior taxa de metabolização da glicose, maior secreção de insulina em alta glicose e menor expressão protéica das subunidades p47 $7^{\text {phox }}$ e gp91 ${ }^{\text {phox }}$ da $\mathrm{NAD}(\mathrm{P}) \mathrm{H}$ oxidase e diminuição da produção de superóxido em relação aos animais controle. Todos estes resultados indicam que as ilhotas estão regulando a sua atividade e função para compensar os efeitos deletérios da suplementação com gordura saturada animal. Há alguma regulação pós-transcricional ou pós-transducional sobre as subunidades da NAD(P)H oxidase e a diminuição dos níveis protéicos de $\mathrm{p} 47^{\text {phox }}$ e gp91 ${ }^{\text {phox }}$, assim como de superóxido nas células beta indicam que provavelmente esta é uma adaptação à condição do excesso de ácidos graxos e deve estar relacionado ao aumento da secreção de insulina, necessário para compensar a resistência periférica.

Palavras-chave: Dieta hiperlipídica. Estresse oxidativo. Ilhotas de Langerhans. NAD(P)H oxidase. Radical superóxido. 


\section{ABSTRACT \\ VALLE, MMR. NAD(P)H oxidase expression and activity in pancreatic islets from rats treated with high fat diet. 2009. 72 p. Master thesis - Instituto de Ciências Biomédicas, Universidade de São Paulo, São Paulo, 2009.}

In the past few years changes in people's life style, that includes high fat diet and physical inactivity, have raised the incidence of metabolic syndrome. This syndrome is characterized by abdominal obesity, insulin resistance, high triglycerides and low HDL-cholesterol. There are many models to study metabolic syndrome and its related dysfunctions. One of them is the use of high fat diet to simulate a human environmental condition. The kind of fat utilized influences the answer obtained. The lard is often used to obtain an animal model with obesity and insulin resistance, because of its deleterious effect. This kind of diet also causes pancreatic beta cell dysfunction, that is characterized by diminished insulin secretion in vitro and in vivo and even by a reduced insulin mRNA, that is a diabetes mellitus risk factor. Another factor that can contribute to pancreas dysfunction is oxidative stress. The beta cells are indeed sensitive to oxidative stress, because they have low levels of antioxidants enzymes. High fat diet induces oxidative stress and modulates $\mathrm{NAD}(\mathrm{P}) \mathrm{H}$ oxidase expression and activity in many tissues as kidney, aorta, liver, cerebral cortex and adipocytes. Consequently, this enzyme may be involved in many pathophysiological processes such as hypertension, non-alcoholic fatty liver disease, dementia and insulin resistance. Therefore, in pancreatic islets of OLEFT rats (Otsuka Long Evans Tokushima Fatty) and db/db mice, which are models of type 2 diabetes, oxidative stress and high expression of $\mathrm{NAD}(\mathrm{P}) \mathrm{H}$ oxidase were verified, what suggests a role of the enzyme in beta cell dysfunction. There are evidences that this enzyme participates in physiological processes like insulin secretion. Therefore, the objective of this work was to evaluate the action of high fat diet on $\mathrm{NAD}(\mathrm{P}) \mathrm{H}$ oxidase activity and expression and if this fact can be connected to the beta cell dysfunction reported in literature regarding this animal model. Our results show that the high fat diet was effective in promoting a metabolic syndrome-like model. The animals presented abdominal obesity, high systolic arterial pressure, reduced HDL-cholesterol, increased fasting glycemia, hyperinsulinemia and glucose intolerance. However, in pancreatic islets, although there was no difference between the groups for the oxidative stress markers, there was reduced 
apoptosis, increased glucose metabolization and increased insulin secretion at high glucose. Protein expression of $\mathrm{NAD}(\mathrm{P}) \mathrm{H}$ oxidase subunits, gp91 ${ }^{\text {phox }}$ and $\mathrm{p} 47^{\text {phox }}$ was reduced and the superoxide production was diminished also in the high fat diet group when compared to the control group. All these results point to the idea that islets are regulating their activity and function to compensate the deleterious effect of excessive satured animal fat. It is possible that this reduction has a role in the impaired insulin secretion presented by this animal model. There is some pos-transcriptional or pos-translational regulation on $\mathrm{NAD}(\mathrm{P}) \mathrm{H}$ oxidase subunits to reduce the levels of $\mathrm{p} 47^{\text {phox }}$ and gp91 ${ }^{\text {phox }}$ protein, as the diminished superoxide content in beta cells shows that probably there is an adaptation to the fatty acids excess that may be related to the increased insulin secretion, necessary to compensate the peripheral insulin resistance.

Key Words: High fat diet. Islets of Langerhans. NAD $(\mathrm{P}) \mathrm{H}$ oxidase. Oxidative stress. Superoxide radical. 


\section{INTRODUÇÃO}

Com a mudança do estilo de vida da população nos últimos anos, que consome mais gordura e pratica menos exercícios físicos, tem ocorrido um grande aumento na incidência de complicações decorrentes da síndrome metabólica (FULOP et al., 2006; SCHULZE e HU, 2005). A síndrome metabólica é uma agregação de várias disfunções: obesidade abdominal, resistência à insulina, hipertensão, níveis de triglicérides altos e o HDL-colesterol (lipoproteína de altadensidade) baixo. Esta síndrome está associada ao aumento do risco de doença coronariana, derrames e diabetes (OPIE, 2007; RADER, 2007; STOLAR, 2007). Deste modo, a síndrome metabólica tem se tornado um grande problema de saúde pública. Os tratamentos para essas doenças, na maioria das vezes, visam apenas combater os seus efeitos, mas não suas causas. Para o surgimento de medicamentos mais eficazes, é necessário se conhecer melhor os processos moleculares envolvidos em cada uma dessas doenças (FULOP et al., 2006).

Dentre os diversos tipos de modelos animais experimentais que simulam as características da síndrome metabólica, um dos mais interessantes para estudo é o de roedores alimentados com dietas hiperlipídicas, por simular uma condição que muitas vezes reflete um hábito humano (BERTRAN e HANSON, 2001; CESARETTI e KHOLMANN Jr., 2006). Há um grande número de trabalhos com diversos tipos de dietas, de espécies animais e tempos de tratamento. O tipo de gordura utilizada influencia muito os efeitos do tratamento. Entretanto, de maneira geral, a suplementação com gordura é bastante deletéria aos animais, especialmente as baseadas em banha de porco (BRAY et al., 2002; BUETTNER et al., 2006).

Para as células beta pancreáticas, o efeito também é negativo e, a longo prazo, a dieta pode até levar ao diabetes nos animais (WANG et al., 2003). As ilhotas podem apresentar menor expressão do gene da insulina, do GLUT-2, da glicoquinase, da acetilglucosaminiltransferase-IVa e do PDX-1 (AHRÉN et al., 1999; CERF, 2007). A secreção in vitro de insulina estimulada por glicose e/ou ácidos graxos é diminuída em relação aos controles, assim como há registros de diminuição ou aumento do tamanho das ilhotas e hiperinervação colinérgica, que pode ser uma adaptação das ilhotas a resistência à insulina (AHRÉN et al., 1999; CERF, 2007; OKADA et al., 2007; TERAUCHI et al., 2007). No pâncreas de ratos que receberam dieta rica em banha de porco e colesterol houve deposição de gordura, diminuição da microcirculação, aumento do 
estresse oxidativo e diminuição das defesas antioxidantes, o que pode levar a uma pancreatite crônica (YAN et al., 2006).

O excesso de gordura também pode levar ao estresse oxidativo nas células beta, que são muito vulneráveis às espécies reativas de oxigênio, o que pode culminar com a apoptose. A morte celular continuada, por sua vez, ao reduzir a massa de células produtoras de insulina, acaba gerando um quadro de diabetes tipo 2 (CERF, 2007). Células beta incubadas in vitro com alta glicose e ácidos graxos, como o palmitato e o oleato, também apresentam aumento da expressão de fatores pró-apoptóticos, diminuição de fatores anti-apoptóticos e aumento de morte celular por apoptose (MANDRUP-POULSEN, 2001; PIRO et al., 2002). O uso de nicotinamida, um antioxidante, entretanto, preveniu significativamente a apoptose das células beta, indicando que o efeito citotóxico da glicose e dos ácidos graxos livres podem ser mediados pelo estresse oxidativo (PIRO et al., 2002).

Uma das principais fontes do radical ânion superóxido dos organismos é a nicotinamida adenina dinucleotídeo fosfato oxidase ou $\mathrm{NAD}(\mathrm{P}) \mathrm{H}$ oxidase, uma enzima encontrada em células de origem mesodermal (BABIOR, 1999). Ela é amplamente distribuída nos diversos reinos biológicos, estando ausente em procariotos e na maioria dos eucariotos unicelulares, mas presentes em fungos, plantas e animais (BEDARD et al, 2007a). A enzima é composta por várias subunidades, sendo algumas citoplasmáticas e outras ancoradas à membrana plasmática (Figura 1). As subunidades que ficam na membrana são gp91 ${ }^{\text {phox }}$ e $\mathrm{p} 22^{\text {phox }}$, que juntas são chamadas de flavocitocromo b558. Os componentes citoplasmáticos formam dois complexos: um formado por p4 $7^{\text {phox }}$, p $67^{\text {phox }}$ e p40 $0^{\text {phox }}$ e outro por uma subunidade Rac mais RhoGDI, o inibidor da dissociação de GDP da Rac (NAUSSEF, 2008).

A enzima foi inicialmente descoberta e está bem descrita para as células fagocíticas do sistema imunológico, como os neutrófilos, daí a origem do termo phox, abreviação de phagocyte oxidase. Nestas células, a função da enzima é produzir grandes quantidades de radical superóxido para serem usados contra microrganismos (BEDARD et al., 2007b). O descobrimento se deu através de uma doença genética rara ligada ao cromossomo X, que gera imunodeficiência, chamada doença granulomatosa crônica ou CGD, que decorre de mais de quatrocentas mutações diferentes nos diversos componentes do complexo enzimático. O nome deriva do fato da doença gerar um excesso de granulomas nos pacientes. Os defeitos gerados nas proteínas acabam impedindo a produção de superóxido e conseqüentemente as células fagocíticas ficam incapazes 
de matar microrganismos invasores. Esta doença acabou sendo uma enorme fonte de estudo para a descrição da enzima e seus componentes (BABIOR, 1999; BEDARD et al., 2007b; HORDJIK, 2006).

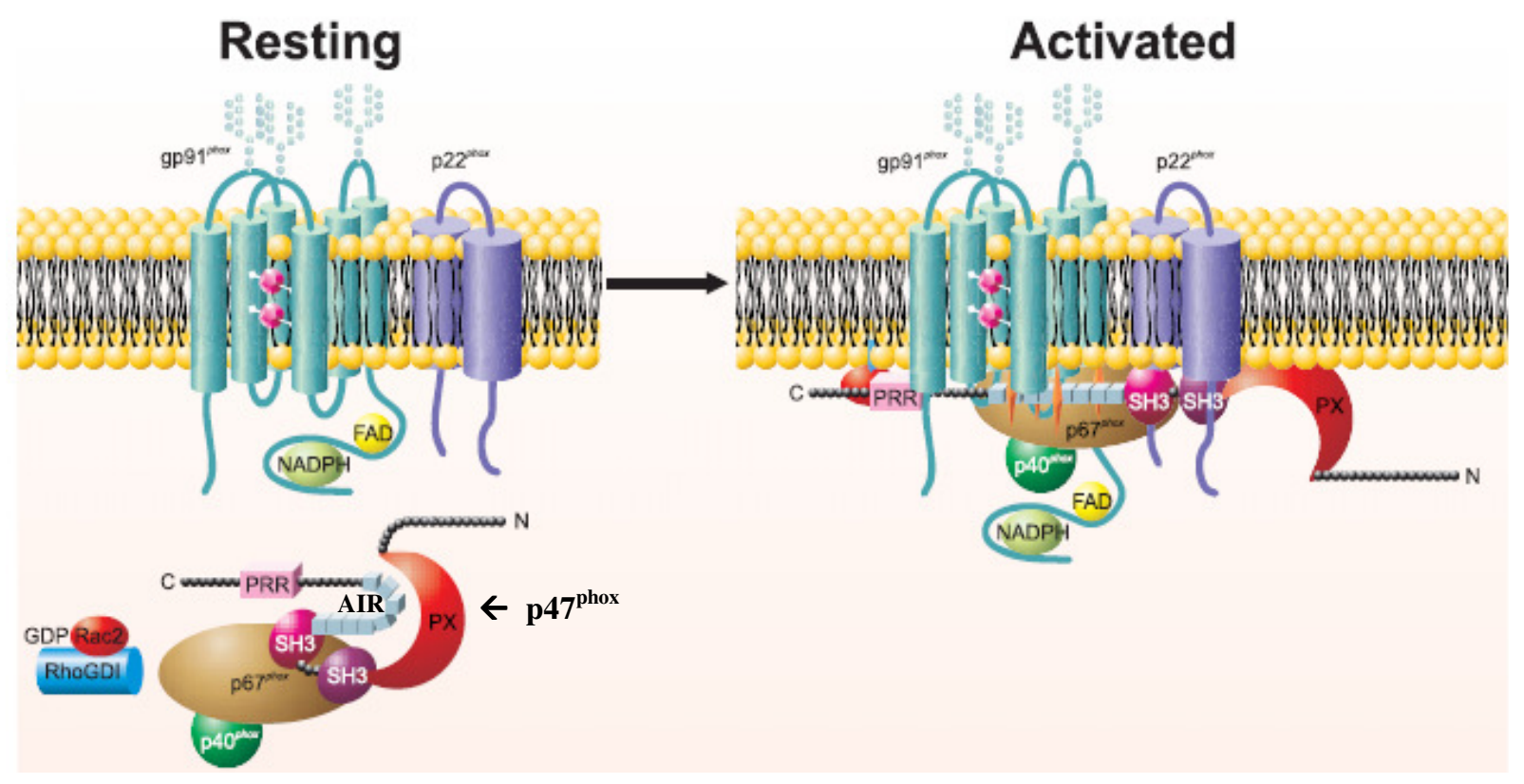

Figura 1- Estrutura da enzima $\operatorname{NAD}(\mathbf{P}) \mathrm{H}$ oxidase fagocítica em seu estado basal e ativado. Está apresentada em detalhes a estrutura tridimensional proposta para gp $91^{\text {phox }}$ e $\mathrm{p} 22^{\text {phox }}$, subunidades ancoradas à membrana. A primeira possui seis alfa-hélices, dois grupos heme distintos (bolas rosas), domínios de ligação citoplasmáticos para o NADPH e FAD e pontos de glicosilação nos loops extracelulares, enquanto a segunda possui apenas dois domínios alfa-hélice trans-membrana. Também são mostradas as subunidades citoplasmáticas, o dímero Rac-RhoGDI, e o trímero $\mathrm{p} 67^{\text {phox }}, \mathrm{p} 47^{\text {phox }}$ e $\mathrm{p} 40^{\text {phox }}$. Os domínios presentes na subunidade organizadora, ou $47^{\text {phox }}$, também são mostrados: PRR - ou região rica em prolina; AIR região auto-inibitória; SH3 - domínio de homologia à Src 3; e PX - ou domínio de homologia à phox. Para mais detalhes vide o texto.

FONTE: Modificado de Naussef, 2008.

A subunidade gp91 ${ }^{\text {phox }}$ é uma glicoproteína transmembrana de $91 \mathrm{KDa}$. Apesar de que sua estrutura tridimensional ainda não foi determinada por cristalografia de raios $\mathrm{x}$, dados de mutagênese indicam que ela transpassa a membrana com seis alfa-hélices e possui em sua estrutura dois grupos heme não idênticos ligados em bihistidinas e direcionados paralelamente às hélices (Figura 1). Também possui domínios de ligação a FAD e NADPH (HORDJIK, 2006; NAUSSEF, 2008). Aparentemente a subunidade possui três pontos de glicosilação em resíduos de asparagina localizados no segundo e terceiro loop extracelular. Os principais carboidratos envolvidos são $\mathrm{N}$-acetilglicosamina e galactose e, em menor quantidade, frutose, manose, e 
glicose. Ela se colocaliza na membrana plasmática com a proteína transmembrânica p $22^{\text {phox }}$ de 22 KDa. Esta também ainda não teve sua estrutura desvendada, mas acredita-se que seja formada por duas alfa-hélices e que suas extremidades $\mathrm{C}$ e $\mathrm{N}$-terminal sejam voltadas para o citoplasma (BEDARD et al., 2007b). A associação entre gp91 ${ }^{\text {phox }}$ e p22 $2^{\text {phox }}$ se dá na proporção $1: 1$ e é completamente necessária para a atividade da enzima, pois apenas a união das duas subunidades gera um complexo estável para a ancoragem dos outros componentes da enzima e produção de superóxido (MIYAMO e SUMIMOTO, 2007). Além disso, em células mielóides é necessária a co-expressão das duas subunidades para o egresso do retículo endoplasmático (RE) até a membrana plasmática. A expressão de apenas uma delas ocasiona o aprisionamento no RE e posterior degradação (DELEO et al., 2000). Além disso, pacientes CGD com mutações em apenas uma das duas subunidades, sempre têm ausência de expressão de ambas (HEYWORTH et al., 2003).

As subunidades citoplasmáticas, $\mathrm{p} 67^{\text {phox }}, \mathrm{p} 47^{\text {phox }}$ e $\mathrm{p} 40^{\text {phox }}$, no estado basal se mantem unidas em trímeros no citoplasma em complexos de 240-260 KDa. Elas possuem respectivamente $67 \mathrm{KDa}, 47 \mathrm{KDa}$ e $40 \mathrm{KDa}$, além de diversos domínios para interação com outras proteínas e com fosfolipídios de membrana. A subunidade $\mathrm{p} 47^{\text {phox }}$ possui um domínio PX, ou de homologia à phox, que foi originalmente descoberto como um motivo conservado de cerca de 130 resíduos presente nela e na p40 ${ }^{\text {phox }}$ (COZIER et al., 2007) Este é um domínio de endereçamento para fosfolipídios de membrana, e no caso da $\mathrm{p} 47^{\text {phox }}$ especificamente para o fosfatidil-inositol- $(3,4)$ bifosfato ou PtdIns(3,4)P2 (Figura 2). Esta subunidade também possui o domínio SH3 ou domínio de homologia à $\mathrm{Src} 3$, que é um domínio de interação com a região rica em prolina (PRR) de outras proteínas, sendo que para este a ligação se dá especificamente com a PRR de p22 $2^{\text {phox }}$. Entretanto, este domínio no estado basal, assim como o PX, está coberto pela AIR, ou região auto-inibitória, que possui vários sítios de fosforilação, responsáveis pela ativação da enzima. A p4 $7^{\text {phox }}$ também possui um domínio PRR que interage com o domínio SH3 de p67 $7^{\text {phox }}$ (BEDARD et al., 2007a; NAUSSEF, 2008).

A p $67^{\text {phox }}$, por sua vez, possui várias repetições tetricopeptídeos (TPR) em tandem em sua região N-terminal que interagem com Rac (Figura 2). Também possui a região de ativação, ou $\mathrm{AD}$, que interagirá com gp91 ${ }^{\text {phox }}$. Com $\mathrm{p} 47^{\text {phox }}$ ela interage através de um domínio SH3 (BEDARD et al, 2007b). Além disso, possui o domínio de $\underline{P}$ hox e $\underline{B} e m 1$, ou PB1, de interação com $\mathrm{p} 40^{\text {phox }}$ (TERASAWA et al., 2001). A subunidade $440^{\text {phox }}$ também possui um domínio PB1, 
com o qual interage com $\mathrm{p} 67^{\text {phox }}$, um domínio SH3, de interação com $\mathrm{p} 47^{\text {phox }}$ (ao menos no estado basal) e um domínio PX, de interação com fosfatidil-inositol-trifosfato ou PtdInsP3 (TAMURA et al., 2007 ).

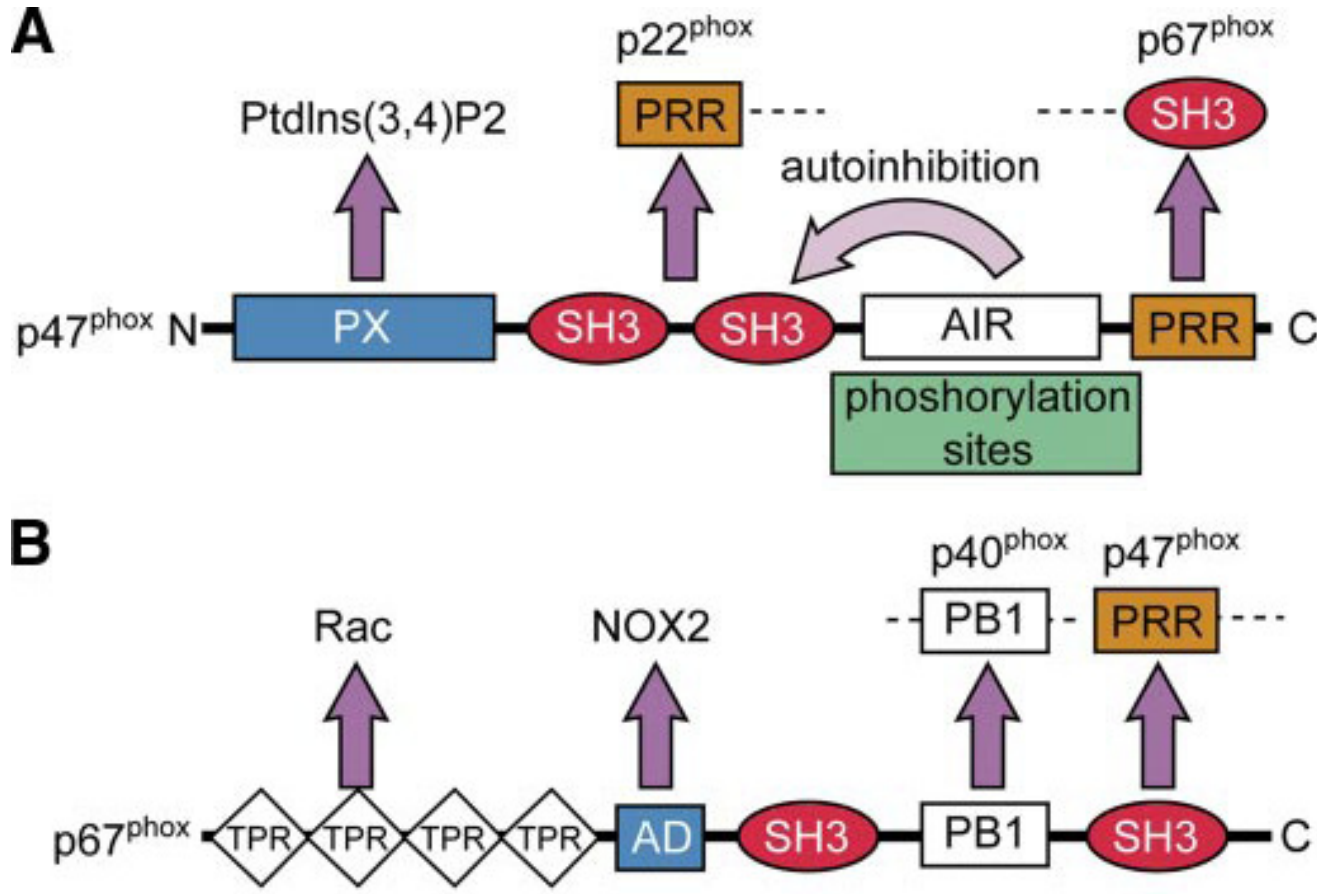

Figura 2- Interações moleculares das subunidades citoplasmáticas p47 $7^{\text {phox }}(A)$ e p67 ${ }^{\text {phox }}(B)$. Abreviaturas (em inglês): PX - domínio de homologia à phox; SH3 - domínio de homologia à Src3; AIR - região autoinibitória; PRR - região rica em prolina; TPR - repetição de tetricopeptídeo; $\mathrm{AD}$ - domínio de ativação; PB1 - domínio de Phox e Bem1; PtdIns(3,4)P2 - fosfatidil-inositol- (3,4)bifosfato. Para mais detalhes vide o texto.

FONTE: Berdard, 2007a.

Há, na verdade, mais de um tipo de isoformas das pequenas GTPases similares a Rho, as chamadas proteínas Rac: Rac1, Rac1b, Rac2 e Rac3. Somente Rac1 e Rac2 foram associadas à produção de superóxido pela $\mathrm{NAD}(\mathrm{P}) \mathrm{H}$ oxidase. Porém, a Rac2 só é expressa em células hematopoiéticas e é a isoforma mais importante para a ativação da enzima em neutrófilos humanos. Já Rac1 é ubiquamente expressa e, deste modo, deve ser a principal responsável pela ativação da enzima nas células não-fagocíticas onde a NADPH oxidase se expressa. Estudos in vitro demonstraram que Rac1 também é capaz de ativar a enzima fagocítica. Apesar de possuírem 92\% de similaridade, as duas não são totalmente redundantes, uma vez que estruturalmente possuem diferenças relevantes para sua atividade. Aparentemente, para as duas isoformas é importante a interação de uma região conservada efetora na parte $\mathrm{N}$-terminal conservada com a 
p67 $7^{\text {phox }}$. Porém, a parte C-terminal é bastante variável entre as diferentes isoformas e é a responsável pela associação aos fosfolipídios de membrana, o que deve acarretar diferenças em suas ações (HORDJIK, 2006). Isto fica claro no trabalho de Roberts e colaboradores (1999) em que os neutrófilos de camundongos deficientes em Rac2, demonstraram uma diminuição de 77\% na produção de superóxido ativada por PMA, mesmo que a expressão de Rac1 tenha se mantida inalterada. Apenas quando houve um estímulo pró-inflamatório as células Rac2 -/- responderam de maneira similar as selvagens. Este fato demonstra que as duas isoformas participam de vias de sinalização específicas e este deve ser um ponto de divergência entre a $\mathrm{NAD}(\mathrm{P}) \mathrm{H}$ oxidase das células fagocitícas, que é predominantemente ativada por Rac2, e das células não-fagocíticas, que seriam ativadas por Rac1.

A NAD(P)H oxidase não produz superóxido no seu estado basal. É necessária a ação de algum agonista para sua ativação (NAUSSEF, 2008). O controle de sua atividade depende principalmente da compartimentalização de seus componentes. Também envolve um processo bem coordenado que engloba alguns passos subseqüentes: fosforilação, ativação de GTPase e interação entre proteínas, sendo cada um destes, possíveis pontos de regulação de sua ativação (HORDJIK, 2006). Quando ocorre algum estímulo para a ativação da enzima, os dois alvos a serem fosforilados são $\mathrm{p} 47^{\text {phox }}$ e RhoGDI, que sofrem mudanças estruturais e permitem a migração dos componentes para a membrana (Figura 1). A subunidade p47 $7^{\text {phox }}$ quando fosforilada na sua região auto-inibitória expõe seus domínios PX, SH3 e região rica em prolina que interagem com p22 $2^{\text {phox }}$ e fosfolipídios de membrana. A p $47^{\text {phox }}$ é chamada de organizadora por não possuir atividade catalítica, mas por criar condições para que a subunidade ativadora, p67 $7^{\text {phox }}$, regule a redução do FAD pelo NADPH. Já a RhoGDI quando é fosforilada, permite a reposição do GTP na Rac, o que a torna ativa. A Rac-GTP migra independentemente para a membrana e auxilia na ativação do centro catalítico através da sua interação direta com a oxidase e/ou com a p67 ${ }^{\text {phox }}($ NAUSSEF, 2008).

A subunidade $\mathrm{p} 40^{\mathrm{phox}}$ parece contribuir com a afinidade entre os componentes do complexo enzimático, porém, sua contribuição in vivo não aparenta ser completamente necessária, uma vez que não há casos de mutação nesta subunidade que levem a doença granulomatosa crônica (LAMBETH et al., 2007). Há uma suposição de que ela possa ter um efeito inibitório sobre o complexo enzimático (LOPES et al., 2004). Entretanto, estudos mais recentes em sistemas in vitro contendo apenas com o citocromo b558, p6 $7^{\text {phox }}$, Rac e $\mathrm{p} 40^{\text {phox }}$, demonstram que esta sim é 
capaz de ativar a produção de superóxido, de maneira similar a $447^{\text {phox }}$, porém sendo menos eficiente no papel de organização. Isso se deve à ligação competitiva das duas subunidades ao mesmo sítio de $\mathrm{p} 22^{\text {phox }}$. Isto também pode explicar parcialmente o possível efeito inibitório de p40 ${ }^{\text {phox }}$ sob a ativação da oxidase. Outra possível razão seria a regulação diferencial da enzima pela subunidade fosforilada. De qualquer modo, é provável que tanto $\mathrm{p} 47^{\text {phox }}$ quanto $\mathrm{p} 40^{\mathrm{phox}}$ tenham papéis fisiológicos distintos e relevantes, porém estes ainda não estão bem delimitados e compreendidos (TAMURA et al., 2007 ).

Quando as subunidades citoplasmáticas se ligam às subunidades da membrana (gp91 ${ }^{\text {phox }} \mathrm{e}$ p22 $2^{\text {phox }}$ ) a enzima está pronta para catalisar a produção de superóxido (FONTAYNE et al., 2002). $\mathrm{O}$ centro catalítico que promove a transferência do elétron do $\mathrm{NAD}(\mathrm{P}) \mathrm{H}$ para o $\mathrm{O}_{2}$ é a subunidade gp91 ${ }^{\text {phox }}$ (GEISZT e LETO, 2004). A subunidade gp91 $1^{\text {phox }}$ é formada por seis regiões transmembrana alfa-hélices em sua parte $\mathrm{N}$-terminal enquanto sua parte C-terminal é citoplasmática e possui os domínios de ligação ao FAD e NADPH , essenciais para sua atividade (HORDJIK, 2006). Nas terceira e quinta hélices da proteína estão dois resíduos de histidina que são os prováveis ligantes de ferro dos dois grupos hemes não idênticos, sendo um externo à membrana e outro interno. Deste modo, como eles são perpendiculares à superfície da membrana, os elétrons são transferidos do NADPH citoplasmático para o FAD e através da membrana pelos grupamentos hemes até o oxigênio molecular, produzindo então o radical superóxido (SUMIMOTO, 2008).

Com a disponibilização do genoma humano em rede mundial, foi possível encontrar proteínas homólogas ao centro catalítico gp91 ${ }^{\text {phox }}$, que compõem uma família chamada NOX/DUOX com sete membros (Figura 2). A subunidade gp91 ${ }^{\text {phox }}$ foi redenominada de NOX2. As outras são NOX1, 3, 4 e 5 e DUOX1 e 2, todas homólogas ao NOX2. A NOX1 é encontrada principalmente no cólon, a NOX2 em células fagocíticas do sistema imune, NOX3 no ouvido interno, NOX4 nos rins e células sanguíneas, NOX5 em tecidos linfóides e nos testículos e as DUOX na tireóide. Entretanto, todas também são expressas em outros tecidos (BEDARD et al., 2007a). Elas diferem basicamente na dependência ou não de ativadores, no requerimento ou não de p22 $2^{\text {phox }}$, de cofatores citoplasmáticos e de cálcio e na presença ou não de domínios EF-Hands, que são os responsáveis pela ligação ao cálcio e consequente modulação pelo mesmo. Apenas as DUOX possuem um domínio transmembrana adicional que se conecta com outro domínio extracelular, o qual possui uma sequência de homologia às peroxidases. Por isso, há o 
questionamento se ela é capaz de produzir superóxido ou peróxido de hidrogênio (NAUSSEF, 2008).

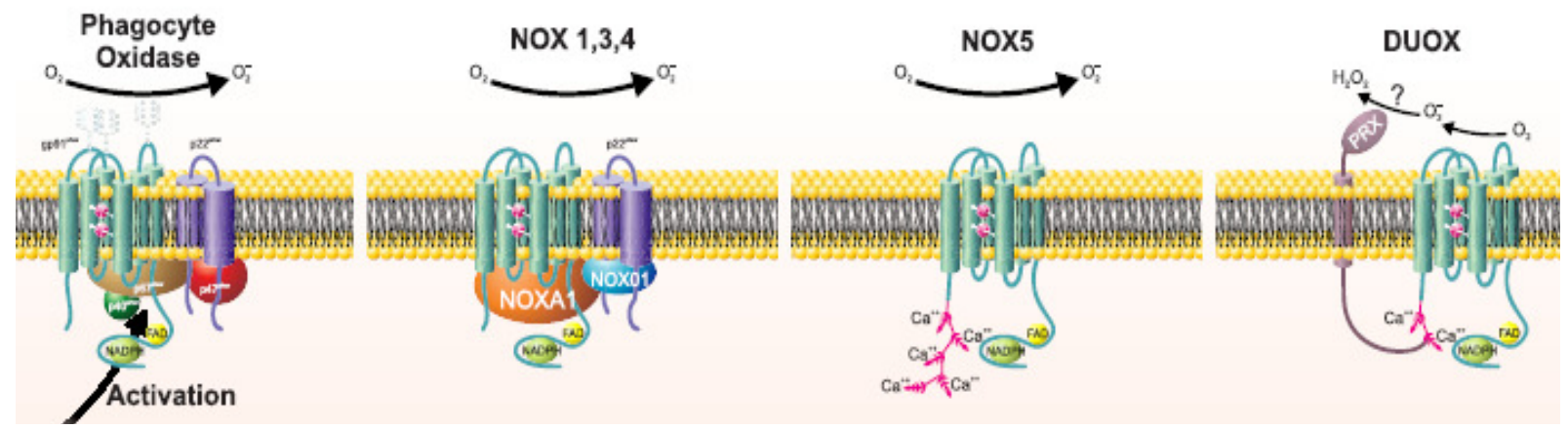

Figura 3- Tipos de estruturas da família de enzimas NOX/DUOX. Enquanto NOX 1,2,3 e 4 são dependentes de p22 $2^{\text {phox }}$, NOX5 e as DUOX não. Essas isoformas ao contrário das outras, não dependem de subunidades regulatórias e são moduladas pelo cálcio, pois possuem o domínio EF-Hands de ligação ao íon.

FONTE: Naussef, 2008.

Além dessas proteínas homólogas à gp91 $1^{\text {phox }}$, há também homólogas a outras subunidades da enzima, como NOXO1 ou Proteína organizadora de NOX, homóloga à p47 phox e NOXA1 ou Proteína ativadora de NOX, homóloga à p67 ${ }^{\text {phox }}$ (BEDARD et al., 2007b). Nem todas as NOX dependem dessas subunidades organizadoras e ativadoras para a produção de superóxido e há uma sobreposição das subunidades organizadoras/ativadoras para a ação dos centros catalíticos. Um estudo in vitro com NOX3, por exemplo, demonstrou que esta produz superóxido apenas associada a p22 $2^{\text {phox }}$. Tanto NOXA1 quanto $\mathrm{p} 47^{\text {phox }}$ podem potencializar sua ação, mas não são estritamente necessárias (UENO et al., 2005).

Em 2003, foi descrito por nosso grupo a expressão da NAD(P)H oxidase (ou NOX2) nas células beta pancreáticas (OLIVEIRA et al., 2003). Uchizono e colaboradores em 2006 demonstraram através de RT-PCR e subseqüente seqüenciamento dos fragmentos obtidos, que além da NOX2 nas ilhotas pancreáticas, há a presença de NOX1, NOX4, p22 $2^{\text {phox }}, \mathrm{p} 47^{\text {phox }}$, NOXA1, NOXO1 e p40 ${ }^{\text {phox }}$. Em 2007 um artigo publicado por nosso grupo demonstrou que a enzima pode ter sua expressão e atividade alterada através da exposição in vitro à citocinas próinflamatórias, palmitato e glicose tanto em uma linhagem de células beta quanto em ilhotas pancreáticas de ratos (MORGAN et al., 2007).

Não se sabe ainda a função exata para a enzima nestas células. É provável, porém, que ela participe de mecanismos fisiológicos, pois está relacionada ao processo de secreção de insulina. 
Em alta concentração de glicose (16,7 mM de glicose), a inibição da enzima por DPI (difenilenoiodônio, inibidor farmacológico da NAD(P)H oxidase), causa diminuição da secreção de insulina de forma dose-dependente (UCHIZONO et al., 2006). Imoto e seu grupo em 2008, na tentativa de elucidar esta ação do DPI na diminuição da secreção, testaram os efeitos do fármaco sobre a secreção de insulina estimulada por glicose e outros secretagogos, no metabolismo da glicose nas ilhotas e no cálcio intracelular $\left([\mathrm{Ca}]_{\mathrm{i}}\right)$ das células beta pancreáticas. Eles verificaram que a disfunção provocada pelo DPI está relacionada a uma alteração na sinalização do cálcio e sugeriram que a $\mathrm{NAD}(\mathrm{P}) \mathrm{H}$ oxidase possa modular a sinalização deste íon nas células beta (IMOTO et al., 2008). Um trabalho subseqüente, realizado em nosso laboratório, também demonstra que a inibição da enzima utilizando DPI ou oligos anti-sense para $47^{\text {phox }}$ gera redução da secreção de insulina estimulada por glicose que é acompanhada por uma diminuição da resposta do cálcio intracelular, da oxidação de glicose e da expressão gênica de GLUT2 e glicoquinase. Estes dados indicam a importância da produção de superóxido pela NADPH oxidase durante o processo de secreção de insulina estimulado por glicose e no metabolismo das células beta (MORGAN et al., 2009). Em concordância com estes resultados, foi demonstrado em células endoteliais, que um considerável transiente de cálcio é causado pela ação do superóxido extracelular sobre receptores de inositol-3-fosfato ou IP3 (MADESH, 2005). Efeito similar nas células beta pode influenciar o processo de secreção da insulina, que é dependente de um aumento de cálcio intracelular transitório.

É sabido que as espécies reativas de oxigênio influenciam processos como expressão gênica, proliferação e morte celular, além de ativar redes de sinalização como as das proteínas quinases ativadas por mitógeno (MAPK), atuar sobre canais de íons como o do cálcio e sobre a atividade quinase do receptor de insulina humano (GENESTRA, 2007). Deste modo, o superóxido produzido pela enzima, deve ter alguma função de sinalização importante nas células beta. A NAD $(\mathrm{P}) \mathrm{H}$ oxidase também pode modificar o potencial de membrana através de sua atividade eletrogênica e pela geração de $\mathrm{H}^{+}$. Acreditava-se que a gp91 ${ }^{\text {phox }}$ pudesse mediar o transporte de $\mathrm{H}^{+}$através da membrana (GENESTRA, 2007; SCHRENZEL et al., 1998). Entretanto, após 2006, ano em que foram descobertos genes para canais de prótons, descobriu-se que a NOX2 fagocítica é intimamente associada a estes canais, que compensam a despolarização e a acidificação do pH citoplasmático causadas por sua atividade (BEDARD, 2007a; DECOURSEY, 2008). Esta nova faceta da enzima tem sido estudada em células do sistema 
imune, porém nada se sabe ainda em células não fagocíticas e, com certeza, a despolarização causada pela enzima poderia influenciar células secretoras, como as produtoras de insulina, mas estas ainda são apenas especulações.

Outra questão se relaciona com o destino do superóxido produzido. $\mathrm{O}$ fato de a estrutura tridimensional das isoformas de NOX não estar completamente desvendada deixa dúvida quanto a este fato. Nos fagócitos em estado basal, a maior parte do flavociocromo b558 é encontrada na membrana de vesículas citoplasmáticas. Quando ocorre uma ativação, as vesículas são fundidas à membrana e a produção de superóxido ocorre para o exterior da célula (BEDARD, 2007a). Nas células foliculares da tireóide todo o peróxido de hidrogênio $\left(\mathrm{H}_{2} \mathrm{O}_{2}\right)$ produzido é extracelular. Além disso, em células endoteliais após estimulação, o radical superóxido também é gerado para o meio extracelular, onde será convertido a peroxinitrito $\left(\mathrm{ONO}_{2}^{-}\right)$ou $\mathrm{H}_{2} \mathrm{O}_{2}$, participando do processo de sinalização envolvido na regulação do tônus vascular. Deste modo, é de se supor que em todas as células não-fagocíticas as NOX presentes na membrana plasmática também produziriam superóxido para o meio extracelular. Então, este seria muitas vezes prontamente convertido em $\mathrm{H}_{2} \mathrm{O}_{2}$ pela superóxido dismutase extracelular (SOD-EC). $\mathrm{O} \mathrm{H}_{2} \mathrm{O}_{2}$, que é difundível pela membrana plasmática, adentraria a célula e efetuaria sua sinalização em questão, como no caso do endotélio. De maneira similar, esta seria uma forma de produzir, sob fina regulação, outras moléculas pró-oxidantes a partir do superóxido gerado por NOX2. Estas então, adentrariam a célula e exerceriam os efeitos pertinentes (STONE e YANG, 2006). Porém, no endotélio e em células musculares lisas vasculares foi relatada a presença de proteínas NOX em membranas internas, como no núcleo, cavéolas, adesões focais e RE (HORDJIK, 2006). Mesmo assim, a produção do radical não seria nunca para o citoplasma, sempre para o exterior ou para dentro de vesículas ou organelas (STONE e YANG, 2006).

Entretanto, pode ser que o superóxido produzido pela $\mathrm{NADP}(\mathrm{H})$ oxidase adentre a célula através do canal 3 para $\mathrm{Cl}^{-}$e que o $\mathrm{H}_{2} \mathrm{O}_{2}$ produzido pela dismutação do superóxido também entre na célula através de aquaporinas (Figura 4). De qualquer modo, a localização e o destino do superóxido produzido devem variar com as funções desempenhadas por este e pelo tipo celular. Há endossomos de sinalização, formados por membrana internalizada, contendo apenas NOX2 e o canal para cloro. Acredita-se que eles produzam superóxido internamente e sirvam para iniciar cascatas de sinalização em locais intracelulares específicos. Deste modo, a sinalização através de NOX2 deve ser dependente do fluxo transmembrana de EROS (FISHER, 2009). 


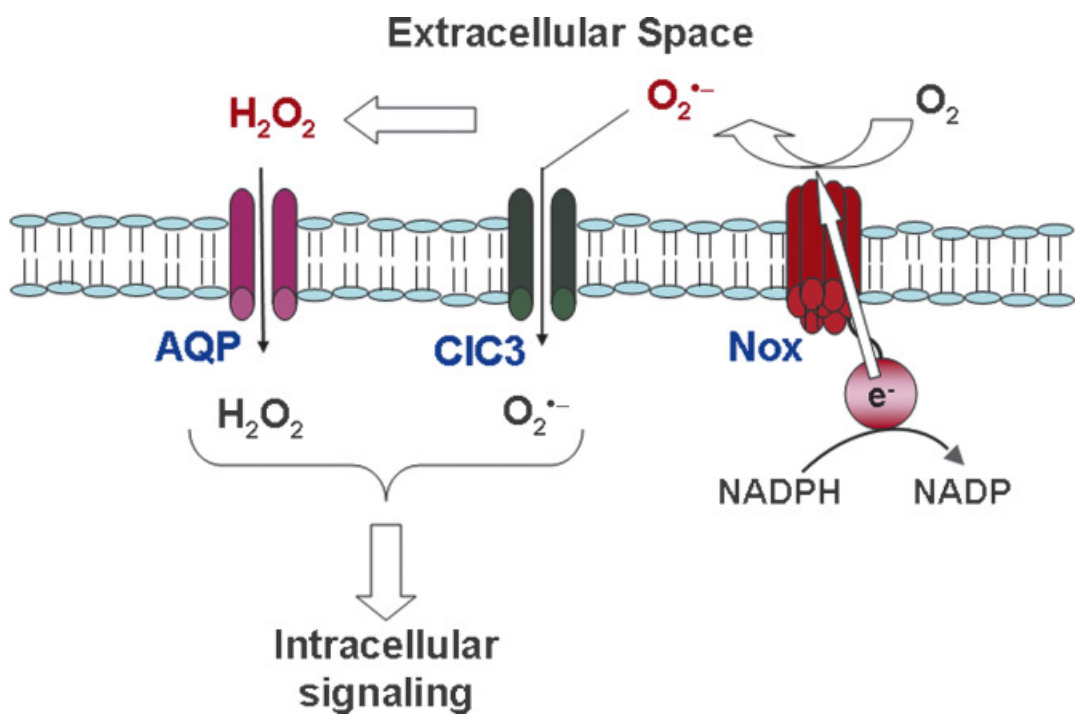

Figura 4- Local de produção e destino do superóxido. O superóxido é produzido para o meio extracelular e entra na célula através do canal 3 pra cloro $(\mathrm{ClC} 3)$ ou é dismutado a peróxido de hidrogênio e adentra o meio intracelular através de aquaporinas (AQP).

FONTE: Fisher, 2009.

Há a possibilidade de que a NAD(P)H oxidase atue também em processos fisiopatológicos, já que pode colaborar para o estresse oxidativo, o qual participa do processo de disfunção das células beta no diabetes e na síndrome metabólica. As proteínas da família NOX já têm sido apontadas como possíveis agentes na promoção de resistência à insulina dos hepatócitos e na falência das células beta em situações em que há excesso de glicose e ácidos graxos. Nas células secretoras de insulina, a alteração na homeostase da glicose poderia gerar o estresse do retículo endoplasmático e culminar com a apoptose por estresse oxidativo através da ação de NOX4. O excesso de ácidos graxos livres e glicose poderiam levar também a ativação da PKC e, consequentemente de NOX1 e NOX2. O aumento de EROs acaba levando a ativação de NFkB, diminuindo a transcrição da pró-insulina e gerando até mesmo apoptose das células beta. Mas os efeitos mediados pelas NOX no diabetes tipo 2 não ocorrem apenas na parte endócrina do pâncreas. $\mathrm{O}$ aumento do sistema renina-angiotensina nas células endoteliais de sinusóides altera o influxo de sangue para o órgão e pode alterar a expressão e atividade das oxidases. Além disso, nas células estelares a ativação de NOX2/NOX4 pode gerar proliferação, fibrose e inflamação local. Por fim, neutrófilos e macrófagos residentes podem gerar localmente EROs via NOX2 além de produzirem citocinas pró-inflamatórias que podem ter ações deletérias sobre a massa de células endócrinas (GUICHARD et al., 2008). 


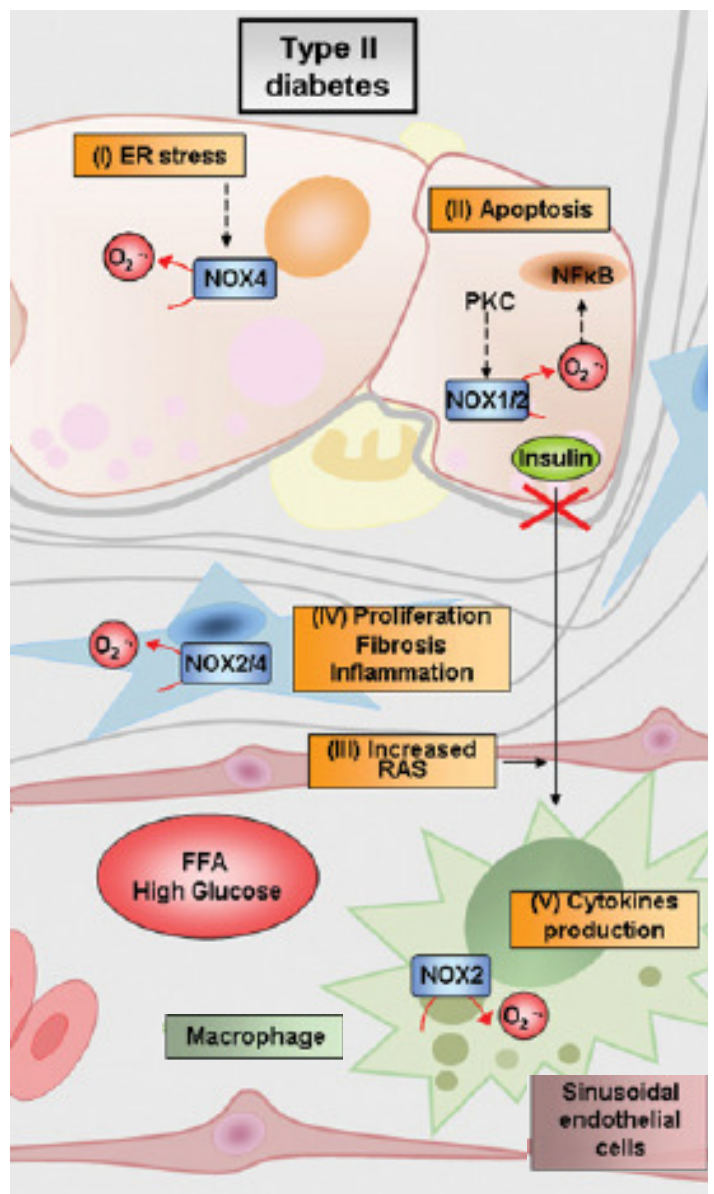

Figura 5- Possíveis ações das proteínas NOX na fisiopatologia do diabetes tipo 2 no pâncreas. Nas células beta: I- O estresse do Retículo Endoplasmático poderia gerar apoptose através da atividade de NOX4 ; IIAtivação de NOX1/2 poderia gerar também não só apoptose, mas ativação de NFkB e diminuição da expressão da pró-insulina. Nas células endoteliais de sinusóides: III- A maior ativação do sistema reninaangiotensina (RAS) poderia também modular a ativação e expressão das proteínas NOX locais. Nas células estelares: IV- A ativação de NOX2/4 poderia gerar aumento da profileração, fibrose e inflamação. Nas células fagocitárias residentes: produção de EROs e citocinas pró-inflamatórias que também poderiam colaborar com o desenvolvimento do diabetes tipo 2.

FONTE: Guichard, 2008.

Já se tem registro de que a NAD(P)H oxidase está ativada em diversos tecidos no diabetes, inclusive nas células beta de ratos OLEFT (Otsuka Long Evans Tokushima fatty) e camundongos db/db, ambos diabéticos tipo 2 (INOGUCHI et al., 2003a; NAKAYAMA et al., 2005). Também existem diversos artigos demonstrando que dietas hiperlipídicas geram aumento da expressão e/ou da atividade da $\mathrm{NAD}(\mathrm{P}) \mathrm{H}$ oxidase em diversos órgãos e tecidos, como rim, aorta, fígado, córtex cerebral e tecido adiposo. O aumento de sua expressão neste tipo de modelo animal está associado à hipertensão, disfunção renal, doença hepática gordurosa não alcoólica, resistência à 
insulina e possivelmente a doenças neurodegenerativas como o Alzheimer (CARMIEL-HAGGAI et al., 2005; MATSUZAWA-NAGATA et al., 2008; ROBERTS et al., 2006; TALIOR et al., 2005; ZHANG et al., 2005). Devido a sua importância como enzima chave na produção de superóxido em diversas disfunções, muitos autores já a têm considerado um possível alvo terapêutico contra o estresse oxidativo (GUICHARD et al., 2008; GUZIK e HARRISON, 2006; INOGUCHI et al., 2003b). 


\section{CONCLUSÕES}

Verificamos que a dieta hiperlipídica é efetiva em produzir obesidade nos animais, especialmente a obesidade visceral, e que ocorrem outras alterações como intolerância à glicose, resistência à insulina e aumento da pressão arterial sistólica. Nossos dados iniciais permitem-nos inferir que as ilhotas isoladas destes ratos não apresentam estresse oxidativo, pela avaliação dos marcadores HNE e nitrotirosina, e apresentam menos morte celular que a dos animais controle, demonstrando que a dieta por apenas três meses não causou efeito deletério para as células beta. Mais um indício de que as células beta estão se adaptando para compensar os efeitos da dieta é o aumento do RNAm de pró-insulina e glicoquinase e a manutenção do GLUT2. A secreção de insulina estática dos animais da dieta hiperlipídica é maior em alta glicose. A taxa de metabolização da glicose está aumentada nas células beta para os animais suplementados com banha de porco. A expressão gênica foi diminuída para NOX1, mas aumentada para as subunidades $\mathrm{p} 47^{\text {phox }}$ e $\mathrm{p} 67^{\text {phox }}$ pela dieta, porém a expressão protéica apresentou-se significativamente menor tanto para $\mathrm{p} 47^{\text {phox }}$ quanto para gp91 ${ }^{\text {phox }}$, o que demonstra haver uma regulação pós-transcricional e/ou pós-traducional controlando a expressão desse complexo enzimático. O conteúdo de superóxido nas ilhotas também esta diminuído para os animais do grupo submetidos à dieta hiperlipídica, resultado coerente com a baixa expressão protéica da NAD(P)H oxidase e a ausência de estresse oxidativo. 


\section{REFERÊNCIAS BIBLIOGRÁFICAS*}

AHRÉN, B. et al. Islets Perturbations in Rats Fed a High-Fat Diet. Pancreas, v. 18, n. 1, p. 75 83, 1999.

ADACHI, Y. et al. Oncogenic Ras upregulates NADPH oxidase 1 gene expression through MEK-ERK-dependent phosphorylation of GATA-6. Oncogene, v. 27, n. 36, p. 4921-32, 2008.

AMMON, H.P. et al. Pentose phosphate shunt, pyridine nucleotides, glutathione, and insulin secretion of fetal islets. Am. J. Physiol., v. 244, n. 4, p.E354-60, Abr., 1983.

ANDERSEN, M. L. et al. Princípios éticos e práticos do uso de animais de experimentação. São Paulo:UNIFESP, 2004. 167 p.

BABIOR, B. M. NAD(P)H axidase: an update. Blood, v. 93, n. 5, p. 1464-1476, Mar., 1999.

BRAY, G. A. et al. The influence of different fats and fatty acids on obesity, insulin resistance and inflammation. J. Nutr., v. 132, p. 2488-2491, 2002.

BEDARD, K. et al. NOX family NADPH oxidases: Not just in mammals. Biochimie, v. 89, p. 1107-1112, Set., 2007a.

BEDARD, K.; KRAUSE, K. The NOX family of ROS-generating NADPH oxidases: physiology and pathophysiology. Physiol. Rev., v. 87, p. 245-313, Jan., 2007 b.

BERTRAN, C. E.; HANSON, M. A. Animal models and programming of the metabolic syndrome. Bri. Med. Bull., v. 60, p. 103-121, 2001.

BINDOKAS, V. E. et al. Visualizing superoxide production in normal and diabetic rat islets of Langerhans. J. Biol. Chem., v. 278, n. 11, p. 9796-9801, Mar., 2003.

BONORA, E. et al. Estimates of in vivo insulin action in man: comparison of insulin tolerance tests with euglycemic and hyperglycemic glucose clamp studies. J. Clin. Endocrinol. Metabol., v. 68, p. 374-378, 1989.

BREWER, A. C.; SPARKSA, E.C.; SHAHA, A.M. Transcriptional regulation of the NADPH oxidase isoform, Nox1, in colon epithelial cells: Role of GATA-binding factor(s). Free Rad. Biol. Med., v. 40, n. 2, p. 260-274, Jan., 2006.

BUETTNER, R. et al. Defining high-fat-diet rat models: metabolic and molecular effects of different fat types. J. Mol. Endocrinol., v. 36, p. 485-506, 2006.

\footnotetext{
*De acordo com:

ASSOCIAÇÃO BRASILEIRA DE NORMAS TÉCNICAS. NBR 6023: Informação e documentação: referências: elaboração. Rio de Janeiro, 2002.
} 
CACHO, J. et al. Validation of simple indexes to assess insulin sensitivity during pregnancy in Wistar ans Spregue Dawley rats. Am. J. Physiol. Endocrinol. Metab., v. 295, n.5, p. E1269-76, Nov., 2008.

CARMIEL-HAGGAI, M; CEDERBAUM, A. I.; NIETO, N. A high-fat diet leads to the progression of non-alcoholic fatty liver disease in obese rats. FASEB J., v.19, n. 1, p. 136-138, Jan., 2005.

CERF, M. E. High-fat diet modulation of glucose sensing in beta-cell. Med. Sci. Monit., v.13 n. 1, p. RA12-17, 2007.

CESARETTI, M. L. R; KHOLMANN Jr., O. Modelos experimentais de resistência à insulina e obesidade: lições aprendidas. Arq. Brás. Endocrinol. Metab., v. 50., n. 2, p. 190-197, Abr., 2006.

CZAKÓ, L. et al. Hyperlipidemia induced by a cholesterol-rich diet aggravates necrotizing pancreatitis in rats. Eur. J. Pharmacol., v. 57, p. 74-81, 2007.

CHALKLEY, S. M. et al. Long-term high-fat feeding leads to severe insulin resistance but not diabetes in Wistar rats. Am. J. Physiol. Endocrinol. Metab., v. 282, p. E1231-E1238, 2002.

CHEN, Z.; NIKI, E. 4-Hydroxynonenal (4-HNE) has been widely accepted as an inducer of oxidative stress. is this the whole truth about it or can 4-HNE also exert protective effects? IUBMB Life, v. 58, n.5-6, p. 372-373, Mai.-Jun., 2006.

COZIER, G.E. et al. The phox homology (PX) domain-dependent, 3-phosphoinositidemediated association of sorting nexin-1 with an early sorting endosomal compartment is required for its ability to regulate epidermal growth factor receptor degradation. J. Biol. Chem., v. 277, n. 50, p. 48730-48736, Dez., 2002.

DECOURSEY, T. E. Voltage-gated proton channels. Cell. Mol. Life Sci., v. 65, p.2554-2573, 2008.

DOBBINS, R. L. et al. The composition of dietary fat directly influences glucose-stimulated insulin secretion in rats. Diabetes, v. 51, p. 1825-1833, Jun., 2002.

DOBRIAN, A. D. et al. Pioglitazone prevents hypertension and reduces oxidative stress in dietinduced obesity. Hypertension, v. 43, p. 48-56, 2004.

FEILLET-COUDRAY, C. et al. Oxidative stress in rats fed a high-fat high-sucrose diet and preventive effect of polyphenols: Involvement of mitochondrial and NAD(P)H oxidase systems. Free Rad. Biol. Med., v. 46, p. 624-632, 2009.

FISHER, A.B. Redox signaling across cell membranes. Antioxid. Redox Signal., v. 11, n. 6, p. 1349-1356, 2009. 
FOLCH. J; LEES, M; SLOANNE STANLEY, G.H. A simple method for isolation and purification of total lipid from animal tissue. J. Biol. Chem., v. 226, p. 497-509, 1957.

FONTAYNE, A. et al. Phosphorylation of $\mathrm{p} 47^{\text {phox }}$ Sites by PKC $\alpha, \beta \mathrm{II}, \delta$ e $\zeta$ : effect on binding to p22 ${ }^{\text {phox }}$ and on NAD(P)H oxidase activation. Biochemistry, v. 41, 7743-7750, 2002.

FULOP, T.; TESSIER, D.; CARPENTIER, A. The metabolic syndrome. Pathol. Biol., v. 54, p. 375-386, 2006.

GALILI, O. et al. Early experimental obesity is associated with coronary endothelial dysfunction and oxidative stress. Am. J. Physiol. Heart Circ. Physiol., v. 292, p. H904-H911, Fev., 2007.

GEISZT, M.; LETO, T. L. The Nox family of NAD(P)H oxidases: host defense and beyond. J. Biol. Chem., v. 279, n. 50, p. 51715-51718, 2004.

GENESTRA, M. Oxyl radicals, redox-sensitive signalling cascades and antioxidants. Cell. Signall., v.19, p.1807-1819, 2007.

GUICHARD, C. et al. NOX family NADPH oxidases in liver and in pancreatic islets: a role in the metabolic syndrome and diabetes? Biochem. Soc. Trans., v.36, p. 920-929, 2008.

GUZIK, T. J.; HARRISON, D. G. Vascular NADPH oxidases as drug targets for novel antioxidant strategies. Drug Discov. Today, v. 11, n. 11, p. 524-533, Jun., 2006.

HASEBE, T. et al. Involvement of cytosolic prolyl endopeptidase in degradation of $\mathrm{p} 40^{\text {phox }}$ splice variant protein in myeloid cells. J. Leukoc. Biol., v. 69, p. 963-968, Jun., 2001.

HEYWORTH, P.G.; CROSS, A.R.; CURNUTTE, J.T. Chronic granulomatous disease. Curr. Opin. Immunol., v. 15, n.5, p. 578-84, 2003.

HIRATA, A.E. et al. Angiotensin II induces superoxide generation via NAD(P)H oxidase activation in isolated rat pancreatic islets. Regul. Pept., v. 153, n. 1-3, p. 1-6, Fev., 2009.

HORDIJK, PL. Regulation of NADPH Oxidases - the role of rac proteins. Circ. Res., v. 98, p. 453-462, 2006.

IMOTO, H. et al. Impaired insulin secretion by diphenyleneiodium associated with perturbation of cytosolic $\mathrm{Ca}^{2+}$ dynamics in pancreatic beta cells. Endocrinology, v.149, n. 11, p. 5391-400, Nov., 2008.

INOGUCHI, T. et al. Protein kinase C-dependent increase in reactive oxygen species (ROS) Production in Vascular Tissuesof Diabetes: Role of Vascular NAD(P)H Oxidase. J. Am. Soc. Nephrol., v. 14, p. S227-232, Ago., 2003 a.

INOGUCHI, T. et al. A posible target of antioxidative therapy for diabetic vascular complications-vascular NAD(P)H oxidase. Curr. Med. Chem., v. 10, n. 17, Set., 2003 b. 
KRIPPEIT-DREWS, P. et al. Interference of $\mathrm{H}_{2} \mathrm{O}_{2}$ with stimulus-secretion coupling in mouse pancreatic $\beta$-cells. J.Physiol., v. 514, n. 2, p. 471-481,1999.

LAEMMLI, U.K. Cleavage of structural proteins during the assembly of the head of bacteriophage T4. Nature, v. 227, n. 5259, p. 680-685, 1970.

LAMBETH, D.J.; KAWAHARA, T.; DIEBOLD, B. Regulation of Nox and duox enzymatic activity and expression. Free Radic. Biol. Med., v. 43, n. 3, p. 319-331, Ago., 2007.

KAKAR, R.; KAUTZ, B.; EKLUND, E.A. JAK2 is necessary and sufficient for interferon- $\gamma$ induced transcription of the gene encoding gp9 ${ }^{\text {phox }}$. J. Leukoc. Biol., v. 77, p.120-127, Jan., 2005.

KAMATA, H.; HIRATA, H. Redox regulation of cellular signalling. Cell. Signal., v. 11, n. 1, p. $1-14,1999$.

KOVACIC, H. N. et al. Redox regulation of human rac1 stability by the proteasome in human aortic endothelial cells. J. Biol. Chem., v. 276, n. 49, p. 45856-45861, Dez., 2001.

LACY, P.E.; KOSTIANOVSKY, M. Method for the isolation of intact islets of Langerhans from the rat pancreas. Diabetes, v. 16, n. 1, p. 35-9, 1967.

LAMBETH, D.J.; KAWAHARA, T.; DIEBOLD, B. Regulation of Nox and Duox enzymatic activity and expression. Free Radic. Biol. Med., v. 43, n. 3, p. 319-331, 2007.

LENZEN, S.; DRINKGERN, J.; TIEDGE, M. Low antioxidant enzyme gene expression in pancreatic islets compared with various other mouse tissues. Free Radic. Biol. Med., v. 20, n. 3, p. 463-466, 1996.

LIVAK, K. J.; SCHMITTGEN, T. D. Analysis of relative gene expression data using real-time quantitative PCR and the $2^{\Delta \Delta c}$ T method. Methods, v. 25, p. 402-408, 2001.

LOPES, LR. et al. Phosphorylated $\mathrm{p} 40^{\mathrm{phox}}$ as a negative regulator of NADPH oxidase. Biochemistry, v. 43, n.12, p. 3723-3730, 2004.

MADESH, M et al. Selective role for superoxide in InsP3 receptor-mediated mitochondrial dysfunction and endothelial apoptosis. J. Cell Biol., v. 170, n. 7, p. 1079-1090, Set., 2005.

MANDRUP-POULSEN, T. $\beta$-Cell Apoptosis: stimulus and signalling. Diabetes, v. 50, p. S5863, Fev., 2001.

MATTHEWS, D.R. et al. Homeostasis model assessment: insulin resistance and beta-cell function from fasting plasma glucose and insulin concentrations in man. Diabetologia, v. 7, p. 412-419, Jul., 1985.

MATSUZAWA-NAGATA, N. et al. Increased oxidative stress precedes the onset of high-fat diet-inducedinsulin resistance and obesity. Metabol. Clin. Exp., v. 57, p. 1071-1077, 2008. 
MIYANO, K.; SUMIMOTO, H. Role of the small GTPase Rac in p22 ${ }^{\text {phox }}$-dependent NADPH oxidases. Biochimie, v. 89, n. 9, p.1133-1144, Set., 2007.

MORGAN, D. et al. Association of NAD(P)H oxidase with glucose-induced insulin secretion by pancreatic beta cells. Endocrinology, v. 150, n. 5, p. 2197-2201, Maio, 2009.

MORGAN, D. et al. Glucose, palmitate and pro-inflammatory cytokines modulate production and activity of a phagocyte-like NADPH oxidase in rat pancreatic islets and a clonal beta cell line. Diabetologia, v. 50, p. 359-369, 2007.

NAKAMURA, S. et al. Palmitate induces insulin resistance in H4IIEC3 hepatocytes through reactive oxygen species produced by mitochondria. J. Biol. Chem., v. 284, n. 22, p. 1480914818, Maio, 2009.

NAKAYMA, M. et al. Increased expression of NAD(P)H oxidase in islets of animal models of type 2 diabetes and its improvement by an AT1 receptor antagonist. Biochem. Biophys. Res. Commun., v. 332, p. 927-933, 2005.

NAUSSEF, W. M. Biological roles for the NOX family NADPH oxidases. J. Biol. Chem., v. 283, n. 25, p. 16961-16965, Jun., 2008.

NICOLETTI, I et al. A rapid and simple method for measuring thymocyte apoptosis by propidium iodide staining and flow cytometry. J. Immunol. Methods, v. 139, n. 2, p. 271-279, 1991.

OLIVEIRA, H. R. et al. Pancreatic $\beta$-Cells EXPRESS PHAGOCYTE-LIKE NAD(P)H oxidase. Diabetes, v. 52, p. 1457-1463, Jun., 2003.

OPIE, L. H. Metabolic syndrome. Circulation, v. 115, p. 32-35, 2007.

OKADA, T. et al. Insulin receptors in $\beta$-cells are critical for islet compensatory growth response to insulin resistance. PNAS, v. 104, n. 21, p. 8977-8982, Maio, 2007.

PETERSEN, D. R.; DOORN, J. A. Reactions of 4-hydroxynonenal with proteins and cellular targets. Free Rad. Biol. Med., v. 37, n. 7, p. 937-945, 2004.

PFAFFL, M. W. A new mathematical model for relative quantification in real-time RT PCR. Nucleic Acids Res., v. 29, n. 9, p. 2002-2007, 2001.

PIRO, S. et al. Chronic exposure to free fatty acids or high glucose induces apoptosis in rat pancreatic islets: possible role of oxidative stress. Metabolism, v. 51, n. 10, p. 1340-1347, Out., 2002.

PUPO, A.D.; MARREIRO, D. Dosage of insulin levels using radioimmunoassay with double antibodies. AMB. Rev. Assoc. Med. Bras., v.16, n. 5, p. 153-156, 1970. 
RADER, D. J. Effect of insulin resistance, dyslipidemia, and intra-abdominal adiposity on the development of cardiovascular disease and diabetes mellitus. Am. J. Med., v. 120, p. S12-S18, Mar., 2007.

ROBERTS, A. W. et al. Deficiency of the hematopoietic cell-specific rho family gtpase rac2 is characterized by abnormalities in neutrophil function and host defense. Immunity, v. 10, p.183196, Fev., 1999.

ROBERTS, C. K et al. Oxidative stress and dysregulation of $\mathrm{NAD}(\mathrm{P}) \mathrm{H}$ oxidase and antioxidant enzymes in diet-induced metabolic syndrome. Metabol. Clin. Exp., v.55, p.928- 934, 2006.

SAELY, C.H.; REIN, P.; DREXEL, H. The metabolic syndrome and risk of cardiovascular disease and diabetes: experiences with the new diagnostic criteria from the international diabetes federation. Horm. Metab. Res., v. 39, p. 642-650, 2007.

SCHRENZEL, J. et al. Electron currents generated by the human phagocyte NADPH oxidase. Nature, v. 392, p. 734-737, Abr., 1998.

SCHULZE, M. B.; HU, F. B. Primary prevention of diabetes: what can be done and how much can be prevented? Annu. Rev. Public Health, v. 26, p.445-67, 2005.

SERRANDER, L. et al. NOX4 activity is determined by mRNA levels and reveals a unique pattern of ROS generation. Biochem. J., v. 406, p. 105-114, 2007.

STOLAR, M. Metabolic syndrome: controversial, but useful. Clevel. Clinic J. Med., v. 74, n. 3, p.199-208, Mar., 2007.

STONE, J.R.; YANG, S. Hydrogen peroxide: a signaling messenger. Antioxid. Redox Signal., n. 8, n. 3- 4, p. 243-270, 2006.

TALIOR, I. et al. PKC- $\delta$-dependent activation of oxidative stress in adipocytes of obese and insulin-resistant mice: role for NADPH oxidase. Am. J. Physiol. Endocrinol. Metab., v. 288, p. E405-E411, 2005.

TAMURA, M. et al. $\mathrm{p} 40^{\text {phox }}$ as an alternative organizer to $447^{\text {phox }}$ in Nox 2 activation: A new mechanism involving an interaction with p22 $2^{\text {phox }}$. FEBS Lett., v. 581, p. 4533-4538, 2007.

TERASAWA, H. et al. Structure and ligand recognition of the PB1 domain: a novel protein module binding to the PC motif. EMBO J., v. 20, n.15, p.3947-56, 2001.

TERAUCHI, Y. et al. Glucokinase and IRS-2 are required for compensatory $\beta$ cell hyperplasia in response to high-fat diet-induced insulin resistance. J. Clin. Invest., v. 117, n. 1, p. 246-257, Jan., 2007.

TOWBIN, H.; STAEHELIN, T.; GORDON, J. Electrophoretic transfer of proteins from polyacrylamide gels to nitrocellulose sheets: procedure and some applications. Proc. Natl. Acad. Sci. USA, v. 76, n.9, p.43050-43054, 1979. 
UCHIZONO, Y. et al. Expression of isoforms of NADPH oxidase components in rat pancreatic islets. Life Sciences, v. 80, p. 133-139, 2006.

UENO, N. et al. The NADPH oxidase Nox3 constitutively produces superoxide in a p22 phox dependent manner. J. Biol. Chem., v. 280, n. 24, p. 23328-23339, Jun., 2005.

VALENTE, A. J. et al. Regulation of NOX1 expression by GATA, HNF-1 $\alpha$, and Cdx transcription factors. Free Rad. Biol. Med., v. 44, n. 3, p. 430-443, Fev., 2008.

VIAPPIANI, S.; SCHULZ, R. Detection of specific nitrotyrosine-modified proteins as a marker of oxidative stress in cardiovascular disease. Am. J. Physiol. Heart Circ. Physiol., v. 290, p. H2167-H2168, 2006.

WANG, Y et al. The develompment of diabetes mellitus in wistar rats kept on a high fat/lowcarbohidrate diet for long periods. Endocrine, v. 22, n. 2, p. 85-92, Nov., 2003.

WANG, Y et al. Glucose intolerance induced by a high fat/low-carbohidrate diet in rats. Endocrine, v. 17, n. 3, p. 185-191, Abr., 2002.

WANG, J. et al. Overfeeding rapidly induces leptin and insulin resistance. Diabetes, v.50, p. 2786-2791, 2001.

YAN, M. Long Term High-Fat Diet Induces Pancreatic Injuries Via Pancreatic Microcirculatory Disturbances and Oxidative Stress in Rat With Hyperlipidemia. Biochem. Biophys. Res. Commun., v. 347, p. 192-199, 2006.

ZHANG, X. et al. High dietary fat induces NADPH oxidase-associated Oxidative Stress and Inflammation in Rat Cerebral Cortex. Exp. Neurol., v. 191, p, 318- 325, 2005. 